\title{
Assessment of Diversity based on Agro-morphological and Quality Characterization of Germplasm Accessions of Rice (Oryza sativa L.)
}

\author{
Kanushree Nandedkar*, A.K. Sarawgi, Mangla Parikh, \\ Ritu R. Saxena and Suman Rawte
}

Department of Genetics and Plant Breeding, College Of Agriculture, Indira Gandhi Krishi Vishwavidyalaya, Raipur (C.G), India

*Corresponding author

\section{Keywords}

Rice, Germplasm, Characterization,

Agro-

morphological,

Quality, Shannon

diversity index

Article Info

Accepted:

20 July 2020

Available Online:

10 August 2020

\section{A B S T R A C T}

To estimate the diversity present in rice germplasm accessions collected from NBPGR, New Delhi, the present investigation was performed involving agro-morphological characterization of 48 rice genotypes based on 36 morphological and 15 agronomical and quality traits which revealed existence of sufficient variability in the germplasm accessions of rice. Among the 48 genotypes, the value of Shannons diversity index ranged between 0 to 1.242 with a mean of 0.524 showing wide range of variations for qualitative traits. The coefficient of variation for all quantitative traits ranged from 1.24 to 19 representing sufficient amount of variations in them. The germplasm accessions viz. IC0135883, IC0116088, IC0115346, EC0290871, IC0115512, IC0098713 were identified as best donors and could be used either as donors in rice breeding program or directly used for development of high yielding varieties with superior grain quality.

\section{Introduction}

Rice has the largest germplasm collections in the world consisting of tremendous genetic variability and serving as store house of elite genes which can further be exploited for enriching the rice cultivars with potential genes of desirable traits. Germplasm can serve as a good source of resistance against biotic and abiotic stresses like drought and insect pest and diseases but they are often inferior to commercial cultivars because of several agronomically undesirable features such as poor plant type, spreading habit, high grain shattering, long awns, purple pericarp and/or red kernel and low yield (Gupta et al., 2014). For better utilization of germplasm accessions and estimation of genetic variability present in germplasm, characterization and evaluation are two important activities to be performed. Agromorphological characterization provides the 
mark of identification being an important tool for differentiating one line or variety from other and it also determine their yield potential, local suitability and ability to deal with biotic and abiotic stresses. So, systematic study and characterization of such germplasm is an important step for utilizing the appropriate donors and protecting the unique rice in present era (Parikh et al., 2012). Characterization can also be utilized for varietal identification in seed production programs, maintaining the genetic purity of a genotype and also DUS testing becomes easy in a well characterized genotype (Avtar et al., 2016). Thus, characterization of these varieties will further contribute towards creating a genetic database for breeding programs strategies in the region (Rawte and Saxena, 2018).

\section{Materials and Method}

The research work was conducted at Research cum Instructional farm, College of Agriculture, Indira Gandhi Krishi Vishwavidyalaya, Raipur, Chhattisgarh. The material for the study consisted of 48 genotypes of rice of which 45 germplasm accessions were received from National Bureau of Plant Genetic Resources (NBPGR), New Delhi along with 3 checks namely Swarna, IGKV-R1244 (Maheshwari) and Indira Sugandhit Dhan (Table-1). The experimental material was grown in Kharif 2018 in Randomized Block Design (RBD) with 2 replications. 21 days old seedlings of each genotype was transplanted manually in 2 rows of $2 \mathrm{~m}$ length maintaining a spacing of $20 \mathrm{~cm}$ between rows and $15 \mathrm{~cm}$ between plants in each row.

Observations for all quantitative traits were recorded on 5 random plants from each genotype and their average values were used for statistical analysis. Range, mean and coefficient of variation for 15 agronomical and quality traits were estimated in order to access the genetic diversity and potential donors for further improvement of rice. The germplasm accessions were also characterized based on 36 morphological traits and the phenotypic frequencies of these traits were used to estimate diversity using ShannonWeaver Diversity Index. The index $(\mathrm{H})$ was calculated as presented by Negassa (1985).

$$
H=-\sum_{i=1}^{n} p i \log p i
$$

Where; $n$ is the number of phenotypic classes for a character and pi is the portion of the total number of entries belonging to the $i^{\text {th }}$ class.

\section{Results and Discussion}

\section{Morphological characterization}

After germination, the observations recorded on agro-morphological traits are presented in Table 2. For coleoptiles colour, among 48 genotypes, $71 \%$ showed green colour, $25 \%$ showed purple and 4\% genotypes showed colourless coleoptiles. At booting stage observations were recorded for all the leaf characters. For basal leaf sheath colour, 79\% genotypes showed green colour, $15 \%$ showed purple colour, $4 \%$ showed purple lines and $2 \%$ showed light purple colour (Fig. 1A and Fig. 2). Similar findings were reported by Umarani et al.2017. Similarly, for Leaf: intensity of green colour, 79\% genotypes showed medium green colour whereas $21 \%$ showed dark green colour leaves.

Leaf: anthocyanin colouration was present in $21 \%$ genotypes and absent in rest of the genotypes. Among the genotypes carrying anthocyanin colouration in leaves, in $90 \%$ genotypes the colouration was distributed on margin only and in rest of the $21 \%$ genotypes anthocyanin colouration was present on tips only. Leaf sheath: anthocyanin colouration 
was reported to be present in $21 \%$ genotypes, whereas it was absent in rest $79 \%$ genotypes. Leaf sheath: intensity of anthocyanin colouration was medium in $50 \%$ genotypes, strong in $30 \%$ genotypes and weak in $20 \%$ genotypes (Fig. 1G).

Leaf: pubescence of blade surface was found to be medium in $81 \%$ genotypes, strong in $45 \%$ genotypes and weak in $15 \%$ genotypes. Leaf: auricles were found to be present in all the 48 genotypes (Similar findings were reported by Sarawgi et al., 2013) but anthocyanin colouration of auricles was colourless in $83 \%$ genotypes, purple in $15 \%$ and light purple in 2\% genotypes (Fig. 3D to E). Similarly, leaf: collar was present in all the 48 genotypes (Similar findings were reported by Sarawgi et al., 2013) among which only $21 \%$ genotypes showing presence of anthocyanin colouration whereas rest $79 \%$ genotypes showed absence of anthocyanin colouration of collar.

Leaf: ligule was found to be present in all the 48 genotypes also all of them having split shape of ligule (Similar findings were reported by Sarawgi et al., 2013) and among them $83 \%$ showed white colour, $13 \%$ showed light purple and $4 \%$ genotypes showed purple ligule colour (Fig. 3A to C). Among 48 genotypes, $88 \%$ showed long length of leaf blade and rest $12 \%$ showed medium length of leaf blade. Similarly $75 \%$ genotypes showed medium width of leaf blade and $25 \%$ showed narrow type of leaf blade. Culm attitude which indicates growth habit of any particular species also showed variation as $63 \%$ genotypes were found to have semi-erect, $31 \%$ with erect and $6 \%$ with open culm attitude. Wide variation was reported for time of heading viz. $67 \%$ genotypes were with medium, $19 \%$ genotypes were early in nature, $10 \%$ were late and $4 \%$ were very late for time of heading (Fig. 1B) similar findings were reported by Umarani et al., (2017). For spikelet: colour of stigma, 69\% genotypes showed white colour, $27 \%$ showed purple colour and 4\% showed light purple stigma colour (Fig. 1F). Among 48 genotypes, anthocyanin coluration of nodes was absent in $94 \%$ genotypes and present only in $6 \%$ of the genotypes (Fig. 7C and D) among which 67\% showed strong anthocyanin colouration of nodes and rest 33\% showed medium anthocyanin colouration of nodes. Anthocyanin colouration of internode was absent in all the 48 genotypes. After time of heading, due to absence of seed setting in 2 genotypes the observations were recorded only on 46 genotypes. For spikelet: densities of pubescence of lemma, $63 \%$ genotypes were categorized into medium, 33\% into strong and $4 \%$ into weak category. Flag leaf: attitude of blade (late observation) was semi-erect in $44 \%$ genotypes, erect in $39 \%$ genotypes and horizontal in 17\% genotypes (Fig 6A to C), (Umarani et al., 2017). Similarly, panicle: curvature of main axis was deflexed in $94 \%$ genotypes, semi-straight in $4 \%$ and drooping in $2 \%$ genotypes. Panicle: awns were found to be absent in $87 \%$ genotypes and present only in $13 \%$ genotypes. Among 13\% genotypes with awns, $50 \%$ were having awns of yellowish white colour, $33 \%$ with reddish brown colour awns and $17 \%$ with yellowish brown colour awns (Fig. 1 E). 50\% were found with medium length of awns, $17 \%$ with long awns and $16 \%$ with short awns (Fig. $1 \mathrm{C}$ and Fig. 5A to D). The distribution of awns in $83 \%$ genotypes was on "whole length" and $17 \%$ genotypes were having distribution of awns on tip only. All the 48 genotypes showed presence of secondary branches among which $85 \%$ were having strong branching, 9\% were having clustered type of secondary branching and 6\% showed weak secondary branching (Fig. 4A to C). Panicle: attitude of branches was erect to semi-erect in $78 \%$ genotypes and semi-erect in $22 \%$ genotypes. Panicle exertion was well exerted in $74 \%$ genotypes, partly exerted in $15 \%$ 
genotypes and mostly exerted in $11 \%$ genotypes (Fig. 7A and B). The time maturity was late in $39 \%$ genotypes, early in $38 \%$ genotypes and medium in $28 \%$ genotypes (Fig. 1 D). Leaf: senescence was medium in all the 48 genotypes.

Thus, some characters were monomorphic, some were bimorphic, some were trimorphic and tetramorphic showing wide range of variations. Similar pattern of distribution was reported by Sajid et al., 2015, Pauchauri et al., 2017, Pragnya et al., 2018 and Rawte and Saxena, 2018.

\section{Shannon-weaver diversity indices}

The Shannon-Weaver diversity indices among the germplasm accessions for 36 morphological traits (Table 2) ranged from 0 to 1.242 with a mean value of 0.524 . The highest value of diversity index 1.242 was obtained for Panicle: Length of longest awn, whereas, lowest value of diversity index of 0 was obtained for Leaf: Auricles, Leaf: collar, Leaf: ligule, Leaf: Shape of ligule, Stem: Anthocyanin colouration of internode, Panicle: Presence of secondary branches and Leaf: Senescence as germplasm accessions exhibited no difference for these traits. Thus, these values of diversity index revealed presence of high diversity in the morphological characters studied and therefore, the germplasm accessions can be effectively utilized for improvements for these traits.

\section{Agronomical and quality characterization}

Only 46 genotypes were subjected to agronomical and quality characterization for 15 traits presented in Table 3. The values for time of heading varied from 83 days to 119 days with a mean value of 100.30 and 1.24 coefficient of variation. Plant height ranged from $81.30 \mathrm{~cm}-163.40 \mathrm{~cm}$ with a mean of
$131.13 \mathrm{~cm}$. About 50\% of the genotypes exhibited plant height in the range of 131-150 and thus, grouped as tall. Reduction in plant height may improve their resistance to lodging and reduce substantial yield losses associated with this trait Pachauri et al (2017). Dwarf plant height was exhibited by EC0268881 (81.3) followed by Swarna (86.2) and Indira Sugandhit Dhan (93.8) and IC0139938 (94.9). The coefficient of variation was found to be $3.81 \%$.

The values of panicle length ranged from $21.50 \mathrm{~cm}$ to $29.95 \mathrm{~cm}$ with a mean value of $25.16 \mathrm{~cm}$. Maximum panicle length contributes positively towards grain yield thus, is an important yield contributing trait. The maximum panicle length was recorded for IC0135772 (29.95) followed by IC0135883 (29.49) and IC0142541 (28.89) with the coefficient of variation being $5.89 \%$. Number of filled grains per panicle was recorded with a range of 55 grains per panicle to maximum 228 grains per panicle. The average value recorded was 124.03 grains per panicle and with $13.01 \%$ of coefficient of variation.

The 100 seed weight ranged from $1.18 \mathrm{~g}$ to $3.31 \mathrm{~g}$ with $3.13 \mathrm{~g}$ with a mean value of 2.16 $\mathrm{g}$ and $3.76 \%$ coefficient of variation. Biological yield ranged from $34.40 \mathrm{~g}$ to $116.13 \mathrm{~g}$. The mean value recorded was $67.67 \mathrm{~g}$ and $13.81 \%$ of coefficient of variation. Harvest index varied from $22.66 \%$ to $44.13 \%$ having a mean value of $32.42 \%$ and coefficient of variation being $13.65 \%$.

Grain yield per plant ranged from $10.30 \mathrm{~g}$ to $39.50 \mathrm{~g}$ and average grain yield of $21.95 \mathrm{~g}$. High grain yield was exhibited in genotypes EC0290871 (39.5g) and IC0135883 (38.3g). The coefficient of variation recorded was $19.00 \%$. Milling (\%) ranged widely from $43.37 \%$ to $78.54 \%$ having a mean milling of $67.57 \%$ and $1.43 \%$ coefficient of variation. A 
range of $35.97 \%$ to $66.29 \%$ was recorded for head rice recovery $(\%)$ having a mean value of $51.61 \%$. High values of head rice recovery are preferred for selection of genotypes. The highest value of head rice recovery was exhibited by EC0268881 (66.11\%) followed by IC0115707 (65.14\%) and EC0290871 $(64.75 \%)$. The coefficient of variation recorded was $1.85 \%$.

Kernel length ranged from $3.80 \mathrm{~cm}$ to 6.75 $\mathrm{cm}$ with an average of $5.50 \mathrm{~cm}$ and 1.29 coefficient of variation. Kernel breadth ranged from $1.65 \mathrm{~cm}$ to $2.65 \mathrm{~cm}$ with a mean of $2.26 \mathrm{~cm}$ and $1.97 \%$ coefficient of variation. Values for Kernel L/B ratio ranged from 1.62 $\mathrm{cm}$ to $3.55 \mathrm{~cm}$ with an average of $2.47 \mathrm{~cm}$ and coefficient of variation being 2.70 .

The Alkali spreading value had a range of 2.00 to 7.00 and a mean of 4.15 . Genotypes with intermediate value of alkali spreading value i.e. 4-5 are always considered best for selection. In the experimental material genotypes viz. IC0538217, IC0115512, IC0115758, IC0134999, IC0134976, IC013 5772, IC0089251, IC0098713, Swarna, IC0115346, IC0142543, IC0538350, IC011 5385, IC0115469, IC0115824, IC0116083, EC0290871，IC0134873，IC0135015, IC013 5883, IC0142533, IC0142540, EC0544860, IC0443805, Maheshwari exhibited intermediate values of alkali spreading value. The coefficient of variation was $6.17 \%$.

Values of gel consistency ranged from 25.00 to 84.50 with a mean of 40.87. The intermediate value of gel consistency i.e. 4160 is considered best and selection is generally done for genotypes with intermediate value of gel consistency. The genotypes fulfilling this criteria are EC0268881 (41.00), Indira Sugandhit Dhan (44.50), IC0135772 (46.00), IC0139938 (49.50), IC0142543 (52.50), IC0134134 (52.50), IC0135883 (54.00), IC0142533 (56.00). The coefficient of variation recorded was $2.65 \%$.

Table.1 Germplasm accessions used as experiment material during Kharif, 2018

\begin{tabular}{|l|l|l|l|l|l|l|l|}
\hline $\begin{array}{l}\text { S. } \\
\text { No }\end{array}$ & Accessions & $\begin{array}{l}\text { S. } \\
\text { No }\end{array}$ & Accessions & $\begin{array}{l}\text { S. } \\
\text { No }\end{array}$ & Accessions & $\begin{array}{l}\text { S. } \\
\text { No }\end{array}$ & Accessions \\
\hline $\mathbf{1}$ & IC0538217 & 13 & IC0115824 & 25 & IC0134999 & 37 & IC0089251 \\
\hline $\mathbf{2}$ & IC0538227 & 14 & IC0116090 & 26 & IC0134976 & 38 & IC0098713 \\
\hline $\mathbf{3}$ & IC0538350 & 15 & IC0116077 & 27 & IC0135015 & 39 & IC0146047 \\
\hline $\mathbf{4}$ & IC0115346 & 16 & IC0116088 & 28 & IC0135170 & 40 & IC0134134 \\
\hline $\mathbf{5}$ & IC0115414 & 17 & IC0116083 & 29 & IC0135552 & 41 & EC0268881 \\
\hline $\mathbf{6}$ & IC0115385 & 18 & EC0545411 & 30 & IC0135772 & 42 & EC0544860 \\
\hline $\mathbf{7}$ & IC0115427 & 19 & IC0461104 & 31 & IC0135883 & 43 & IC0264137 \\
\hline $\mathbf{8}$ & IC0115469 & 20 & EC0290802 & 32 & IC0139938 & 44 & IC0443805 \\
\hline $\mathbf{9}$ & IC0115512 & 21 & EC0290950 & 33 & IC0142533 & 45 & EC0205191 \\
\hline $\mathbf{1 0}$ & IC0115691 & 22 & EC0290871 & 34 & IC0142543 & C1* & Swarna \\
\hline $\mathbf{1 1}$ & IC0115707 & 23 & EC0291283 & 35 & IC0142540 & C2* & Maheshwari \\
\hline $\mathbf{1 2}$ & IC0115758 & 24 & IC0134873 & 36 & IC0142541 & C3* & Indira Sugandhit Dhan \\
\hline
\end{tabular}

* $\mathrm{C} 1, \mathrm{C} 2$ and $\mathrm{C} 3$ taken as checks 
Table.2 Frequency distribution and percentage value of 36 agro-morphological characters studied for the experimental material

\begin{tabular}{|c|c|c|c|c|c|}
\hline $\begin{array}{l}\text { S. } \\
\text { No. }\end{array}$ & Characteristics & Category & $\begin{array}{l}\text { No. of } \\
\text { accessi } \\
\text { ons }\end{array}$ & $\begin{array}{l}\text { Frequency } \\
(\%)\end{array}$ & $\begin{array}{l}\text { Shannon's } \\
\text { diversity index }\end{array}$ \\
\hline \multirow[t]{3}{*}{1} & \multirow[t]{3}{*}{ Coleoptile: colour } & Colourless & 2 & 4 & \multirow[t]{3}{*}{0.723} \\
\hline & & Green & 34 & 25 & \\
\hline & & Purple & 12 & 71 & \\
\hline \multirow[t]{4}{*}{2} & \multirow[t]{4}{*}{ Basal leaf: sheath colour } & Green & 38 & 79 & \multirow[t]{4}{*}{0.679} \\
\hline & & Light purple & 1 & 2 & \\
\hline & & Purple lines & 2 & 4 & \\
\hline & & Purple & 7 & 15 & \\
\hline \multirow[t]{2}{*}{3} & \multirow{2}{*}{$\begin{array}{l}\text { Leaf: intensity of green } \\
\text { colour }\end{array}$} & Medium & 38 & 79 & \multirow[t]{2}{*}{0.512} \\
\hline & & Dark & 10 & 21 & \\
\hline \multirow[t]{2}{*}{4} & \multirow{2}{*}{$\begin{array}{l}\text { Leaf: anthocyanin } \\
\text { colouration }\end{array}$} & Absent & 38 & 79 & \multirow[t]{2}{*}{0.512} \\
\hline & & Present & 10 & 21 & \\
\hline \multirow[t]{2}{*}{5} & \multirow{2}{*}{$\begin{array}{l}\text { Leaf: distribution of } \\
\text { anthocyanin colouration }\end{array}$} & On tips only & 1 & 10 & \multirow[t]{2}{*}{0.325} \\
\hline & & On margins only & 9 & 90 & \\
\hline \multirow[t]{2}{*}{6} & \multirow{2}{*}{$\begin{array}{l}\text { Leaf sheath: anthocyanin } \\
\text { colouration }\end{array}$} & absent & 38 & 79 & \multirow[t]{2}{*}{0.512} \\
\hline & & Present & 10 & 21 & \\
\hline \multirow[t]{3}{*}{7} & \multirow{3}{*}{$\begin{array}{l}\text { Leaf sheath: intensity of } \\
\text { anthocyanin colouration }\end{array}$} & Weak & 2 & 20 & \multirow[t]{3}{*}{1.030} \\
\hline & & Medium & 5 & 50 & \\
\hline & & Strong & 3 & 30 & \\
\hline \multirow[t]{3}{*}{8} & \multirow{3}{*}{$\begin{array}{l}\text { Leaf: pubescence of blade } \\
\text { surface }\end{array}$} & Weak & 7 & 15 & 0.582 \\
\hline & & Medium & 39 & 81 & \\
\hline & & Strong & 2 & 4 & \\
\hline 9 & Leaf: Auricles & Absent & 0 & 0 & 0.000 \\
\hline & & Present & 48 & 100 & \\
\hline 10 & Leaf: anthocyanin & Colourless & 40 & 83 & 0.513 \\
\hline & colouration of auricles & Light purple & 1 & 2 & \\
\hline & & Purple & 7 & 15 & \\
\hline 11 & Leaf: collar & Present & 48 & 100 & 0.000 \\
\hline & & Absent & 0 & 0 & \\
\hline 12 & Leaf: Anthocyanin & Absent & 38 & 79 & 0.512 \\
\hline & colouration of collar & Present & 10 & 21 & \\
\hline 13 & Leaf: ligule & Present & 48 & 100 & 0.000 \\
\hline & & Absent & 0 & 0 & \\
\hline 14 & Leaf: Shape of ligule & Split & 48 & 100 & 0.000 \\
\hline & & Truncate & 0 & 0 & \\
\hline & & Acute & 0 & 0 & \\
\hline 15 & Leaf: colour of ligule & White & 40 & 83 & 0.544 \\
\hline & & Light purple & 6 & 13 & \\
\hline & & Purple & 2 & 4 & \\
\hline 16 & Leaf: length of blade & Medium & 6 & 12 & 0.377 \\
\hline & & Long & 42 & 88 & \\
\hline 17 & Leaf: width of blade & Narrow & 12 & 25 & 0.562 \\
\hline & & Medium & 36 & 75 & \\
\hline 18 & Culm: attitude & Erect & 15 & 31 & 0.831 \\
\hline & & Semi-erect & 30 & 63 & \\
\hline & & Open & 3 & 6 & \\
\hline
\end{tabular}




\begin{tabular}{|c|c|c|c|c|c|}
\hline \multirow[t]{4}{*}{19} & \multirow[t]{4}{*}{ Time of Heading } & Early & 9 & 19 & \multirow[t]{4}{*}{0.952} \\
\hline & & Medium & 32 & 67 & \\
\hline & & Late & 5 & 10 & \\
\hline & & Very late & 2 & 4 & \\
\hline \multirow[t]{3}{*}{$20 *$} & \multirow{3}{*}{$\begin{array}{l}\text { Spikelet: Density of } \\
\text { pubescence of lemma }\end{array}$} & Weak & 2 & 4 & \multirow[t]{3}{*}{0.793} \\
\hline & & Medium & 29 & 63 & \\
\hline & & Strong & 15 & 33 & \\
\hline \multirow[t]{3}{*}{21} & \multirow{3}{*}{$\begin{array}{l}\text { Spikelet: Colour of } \\
\text { Stigma }\end{array}$} & Purple & 13 & 27 & \multirow[t]{3}{*}{0.744} \\
\hline & & White & 33 & 69 & \\
\hline & & Light purple & 2 & 4 & \\
\hline \multirow[t]{2}{*}{22} & \multirow{2}{*}{$\begin{array}{l}\text { Stem: anthocyanin } \\
\text { colouration of node }\end{array}$} & Absent & 45 & 94 & \multirow[t]{2}{*}{0.234} \\
\hline & & Present & 3 & 6 & \\
\hline \multirow[t]{2}{*}{23} & \multirow{2}{*}{$\begin{array}{l}\text { Stem: Intensity of } \\
\text { anthocyanin colouration } \\
\text { of node }\end{array}$} & Medium & 1 & 33 & \multirow[t]{2}{*}{0.637} \\
\hline & & Strong & 2 & 67 & \\
\hline \multirow[t]{2}{*}{24} & \multirow{2}{*}{$\begin{array}{l}\text { Stem: Anthocyanin } \\
\text { colouration of internode }\end{array}$} & Absent & 48 & 100 & \multirow[t]{2}{*}{0.000} \\
\hline & & Present & 0 & 0 & \\
\hline \multirow[t]{3}{*}{$25^{*}$} & \multirow{3}{*}{$\begin{array}{l}\text { Flag leaf: Attitude of } \\
\text { blade(late observation) }\end{array}$} & Erect & 18 & 39 & 1.033 \\
\hline & & Semi-erect & 20 & 44 & \\
\hline & & Horizontal & 8 & 17 & \\
\hline \multirow[t]{3}{*}{$26^{*}$} & \multirow{3}{*}{$\begin{array}{l}\text { Panicle: Curvature of } \\
\text { main axis }\end{array}$} & semi-straight & 2 & 4 & 0.283 \\
\hline & & deflexed & 43 & 94 & \\
\hline & & dropping & 1 & 2 & \\
\hline $27 *$ & Panicle: Awns & absent & 40 & 87 & 0.387 \\
\hline & & present & 6 & 13 & \\
\hline $28 *$ & Panicle: Colour of awns & yellowish white & 3 & 50 & 1.011 \\
\hline & & yellowish brown & 1 & 17 & \\
\hline & & reddish brown & 2 & 33 & \\
\hline 29* & Panicle: Length of longest & short & 1 & 16 & 1.242 \\
\hline & awn & medium & 3 & 50 & \\
\hline & & long & 1 & 17 & \\
\hline & & very long & 1 & 17 & \\
\hline 30* & Panicle: Distribution of & tip only & 1 & 17 & 0.451 \\
\hline & awns & whole length & 5 & 83 & \\
\hline 31* & Panicle: Presence of & absent & 0 & 0 & 0.000 \\
\hline & secondary branches & present & 46 & 100 & \\
\hline $32 *$ & Panicle: Secondary & weak & 3 & 6 & 0.530 \\
\hline & branching & strong & 39 & 85 & \\
\hline & & clustered & 4 & 9 & \\
\hline $33 *$ & Panicle: Attitude of & erect to semi-erect & 36 & 78 & 0.524 \\
\hline & branches & semi-erect & 10 & 22 & \\
\hline $34 *$ & Panicle: Exertion & partly exerted & 7 & 15 & 0.751 \\
\hline & & mostly exerted & 5 & 11 & \\
\hline & & well exerted & 34 & 74 & \\
\hline $35^{*}$ & Time maturity & Early & 15 & 33 & 1.090 \\
\hline & & Medium & 13 & 28 & \\
\hline & & Late & 18 & 39 & \\
\hline $36 *$ & Leaf: Senescence & early & 0 & 0 & 0.000 \\
\hline & & medium & 46 & 100 & \\
\hline & & late & 0 & 0 & \\
\hline
\end{tabular}

*observations are recorded only on 46 genotypes. 
Table.3 Descriptive statistics of 48 germplasm accessions for 15 agronomical and quality traits

\begin{tabular}{|l|l|c|c|c|c|}
\hline S. No. & Characters & Mean & Min. & Max. & CV (\%) \\
\hline $\mathbf{1}$ & Time of heading (days) & 100.30 & 83.00 & 119.00 & 1.24 \\
\hline $\mathbf{2}$ & Plant height (cm) & 131.13 & 81.30 & 163.40 & 3.81 \\
\hline $\mathbf{3}$ & Panicle length (cm) & 25.16 & 21.50 & 29.95 & 5.89 \\
\hline $\mathbf{4}$ & Number of filled grains per panicle & 124.03 & 55.00 & 228.00 & 13.01 \\
\hline $\mathbf{5}$ & 100 seed weight (g) & 2.16 & 1.18 & 3.31 & 3.76 \\
\hline $\mathbf{6}$ & Biological yield (g) & 67.67 & 34.40 & 116.13 & 13.81 \\
\hline $\mathbf{7}$ & Harvest index (g) & 32.42 & 22.66 & 44.13 & 13.65 \\
\hline $\mathbf{8}$ & Grain yield per plant (g) & 21.95 & 10.30 & 39.50 & 19.00 \\
\hline $\mathbf{9}$ & Milling (\%) & 67.57 & 43.37 & 78.54 & 1.43 \\
\hline $\mathbf{1 0}$ & Head rice recovery (\%) & 51.61 & 35.97 & 66.29 & 1.85 \\
\hline $\mathbf{1 1}$ & Kernel length(mm) & 5.50 & 3.80 & 6.75 & 1.29 \\
\hline $\mathbf{1 2}$ & Kernel breadth(mm) & 2.26 & 1.65 & 2.65 & 1.97 \\
\hline $\mathbf{1 3}$ & Kernel L/B ratio & 2.47 & 1.62 & 3.55 & 2.70 \\
\hline $\mathbf{1 4}$ & Alkali spreading value & 4.15 & 2.00 & 7.00 & 6.17 \\
\hline $\mathbf{1 5}$ & Gel consistency & 40.87 & 25.00 & 84.50 & 2.65 \\
\hline
\end{tabular}

Table.4 List of unique genotypes based on morphological characters

\begin{tabular}{|l|l|l|}
\hline Character & Pattern & Accessions \\
\hline Anthocyanin colouration of auricle & Light purple & IC0538227 \\
\hline Anthocyanin colouration of node & Present & IC0538227,IC0134976, IC0115414 \\
\hline Basal leaf sheath colour & Purple lines & IC0116083, IC0134976 \\
\cline { 2 - 3 } & Light purple & EC0544860 \\
\hline Leaf: anthocyanin distribution & on tips only & IC0116083 \\
\hline Colour of stigma & Light purple & EC0545411, IC0142533 \\
\hline Colour of ligule & Purple & IC0098713, IC0134134 \\
\hline
\end{tabular}

Table.5 Promising germplasm accessions with grain yield along with other yield related traits

\begin{tabular}{|l|l|l|l|}
\hline Characters & Promising accessions & Characters & Promising accessions \\
\hline High panicle length & IC0135883, IC0116088 & High HRR & EC0290871, IC0115346 \\
\hline High 100 seed weight & IC0115346 & Gel consistency (41-60) & IC0135883 \\
\hline High milling \% & EC0290871, IC0116088 & $\begin{array}{l}\text { Desirable alkali spreading } \\
\text { value(4-5) }\end{array}$ & $\begin{array}{l}\text { IC0115512, IC0098713, } \\
\text { IC0115346, EC0290871, } \\
\text { IC0135883 }\end{array}$ \\
\hline
\end{tabular}


Fig.1 Frequency distribution and percentage value of different characters in germplasm accessions of rice (A to $G$ )

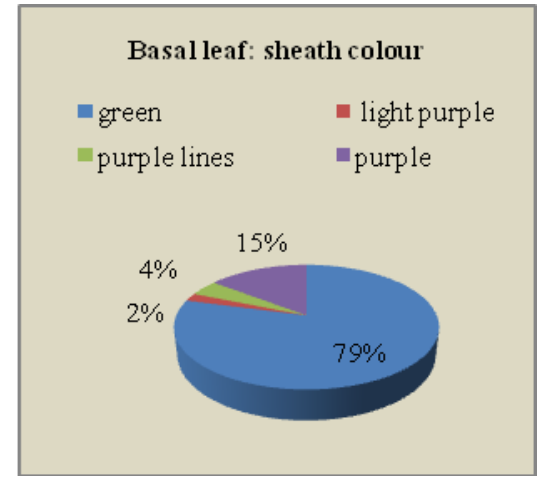

A: Basal Leaf Sheath colour

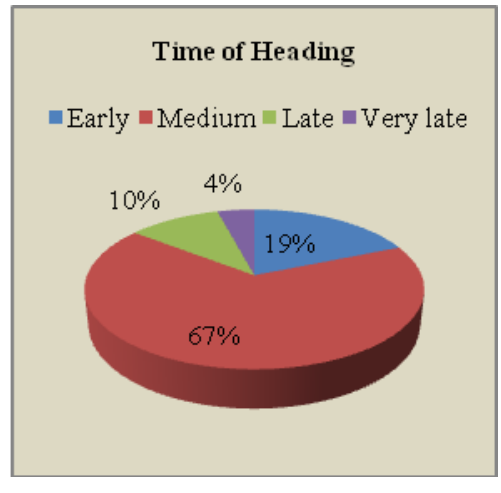

B: Time of Heading

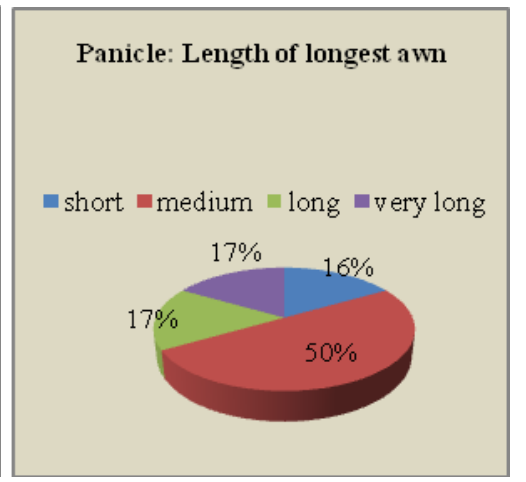

C: Panicle: length of longest awn

\section{Panicle: Colour of awns}

yellowish white yellowish brown reddish brown

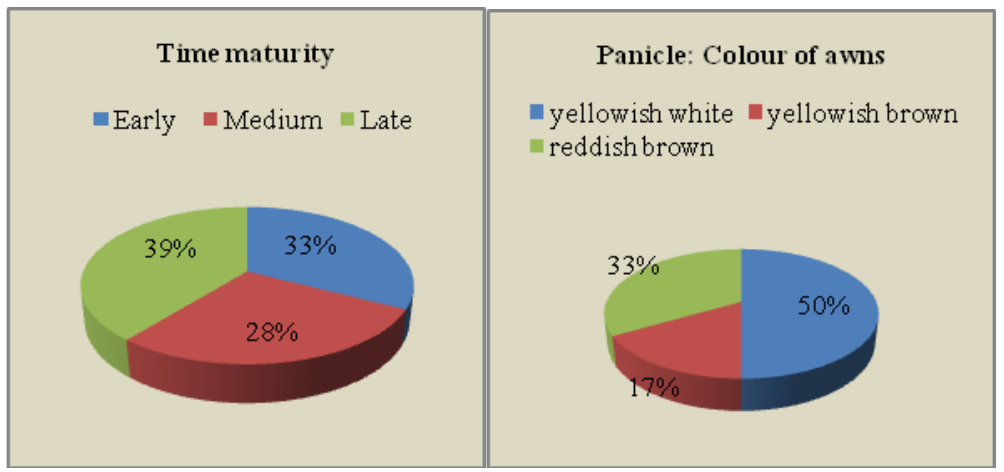

E: Panicle: colour of awn

D: Time maturity

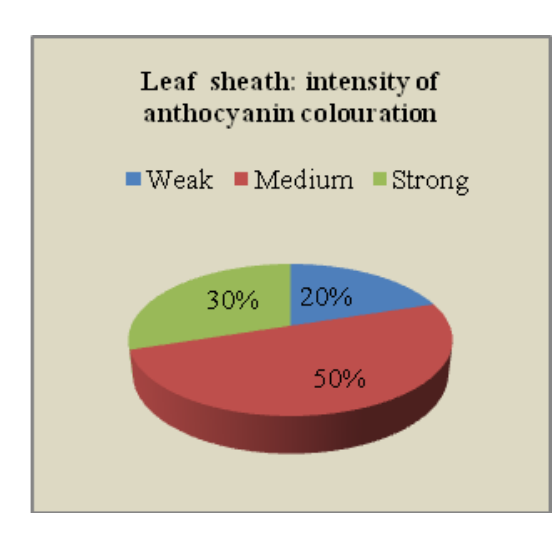

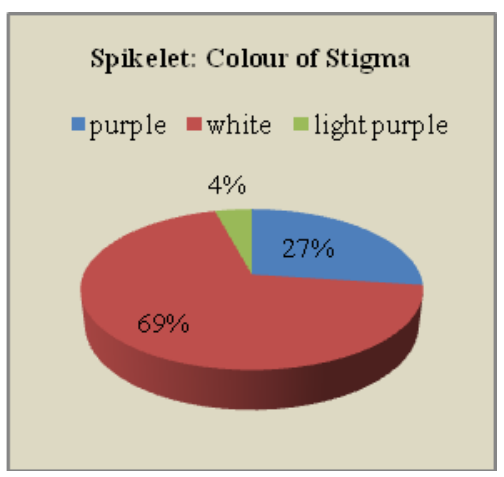

F: Spikelet: Colour of stigma

G: Leaf sheath: intensity of anthocyanin colouration 
Fig.2 Basal leaf sheath colour

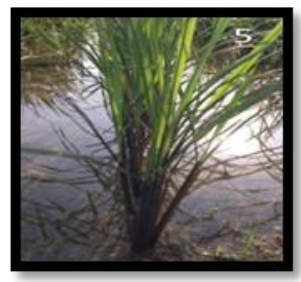

Purple

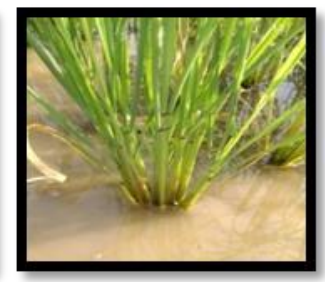

Purple lines

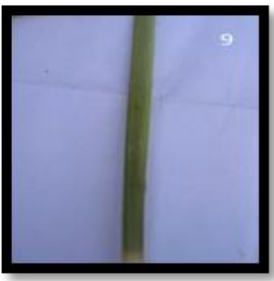

Light Purple

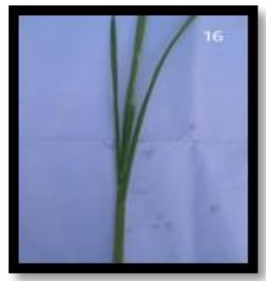

Green

Fig.3 Leaf: colour of ligule (A to C) and Leaf: anthocyanin colouration of auricles (D and E)

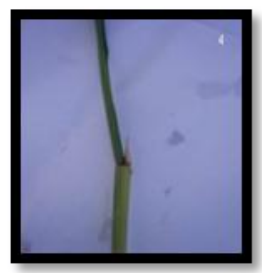

A. Light purple

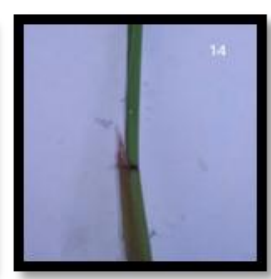

B. Purple

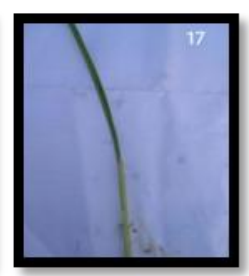

C. White

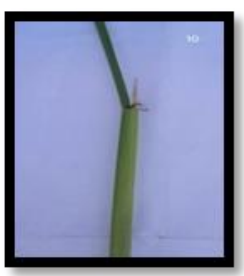

D. Purple

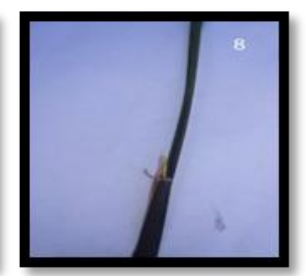

E. Light purple

Fig.4 Panicle: secondary branching

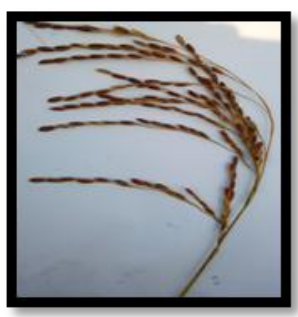

A. Weak

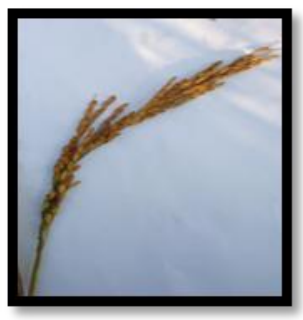

B. Strong

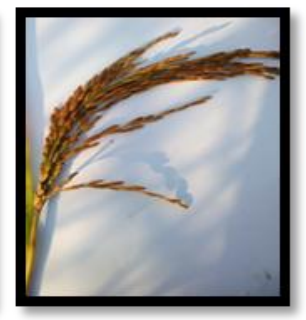

C. Clustered

Fig.5 Panicle: length of longest awn

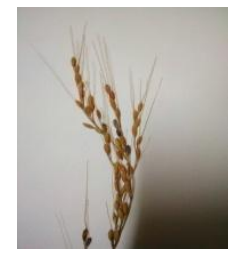

A. Very long

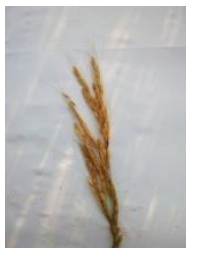

B. Long

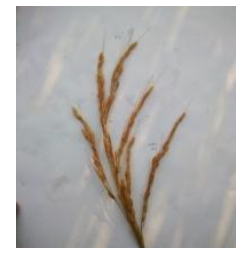

C. Medium

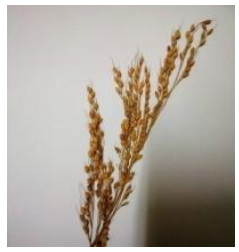

D. Small

Fig.6 Flag leaf: attitude of blade (late observation)

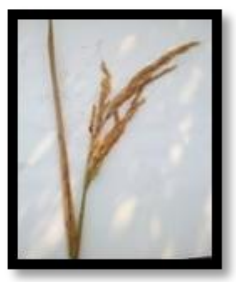

A. Erect

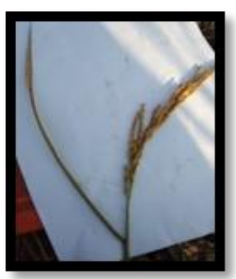

B. Semi-erect

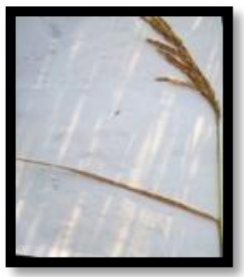

C. Horizontal 
Fig.7 Panicle: exertion (A and B) and Stem: anthocyanin colouration of node (C and D)

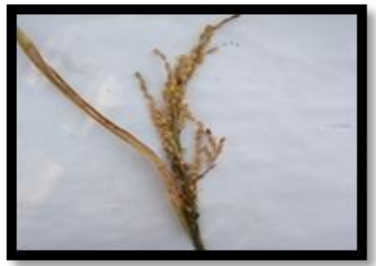

A. Mostly exerted

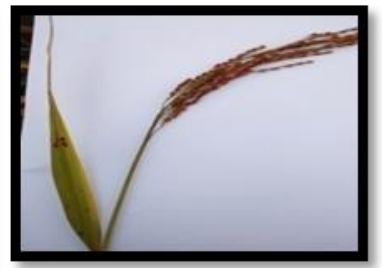

B. Well exerted

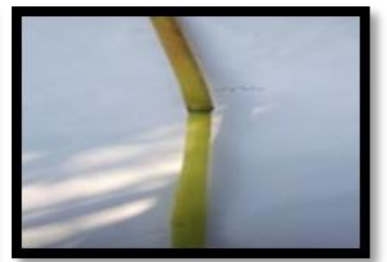

C. Absent

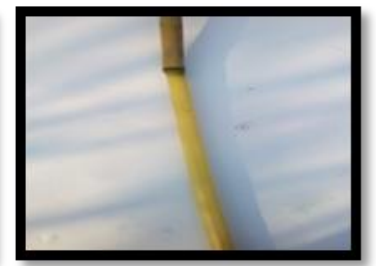

D. Present
After evaluation of 48 rice genotypes for morphological, agronomical and quality characters it was concluded that the accessions viz. IC0538227, IC0116083, IC0134976, EC0544860, EC0545411, IC0142533, IC0098713, IC0134134, IC0115414 were found to be unique (Table 4) which can be utilized as reference variety for DUS testing or can act as morphological marker for distinguishing and future characterization of any germplasm material. The germplasm accessions viz. IC0135883, IC0116088, IC0115346, EC0290871, IC0115512, IC0098713 were identified as promising/ best donors (Table 5) and could be used in rice breeding program or directly used for development of high yielding varieties with superior grain quality.

\section{References}

Avtar, R., Kumari, N., Rani, B., Narula, A., Thakral, N. K. and Singh, D. (2016). Evaluation, classification and characterization of Toria germplasm for different agro-morphological traits. 52 J. Oilseed Brassica, 7(1):52-62.

Gupta, R., Tetwar, S. and Nair, S.K. (2014). Agro-morphological characterization of rice germplasm of Chhattisgarh. Internat. J. Plant Sci., 9 (1): 257-262.

Kumar, V.K., Rastogi, N.K., Sarawgi, A.K., Chandrakar, P., Singh, P.K. and Jena, B.K. 2016. Agro-morphological and quality characterization of indigenous and exotic aromatic rice (Oryza sativa L.) germplasm. Journal of Applied and
Natural Science 8 (1) : $314-320$.

Negassa, M. 1985. Patterns of phenotypic diversity in an Ethiopian barley collection, and the Arussi-Bale Highland as a center of origin of barley. Hereditas 102: 139-150.

Pachauri, A.K., Sarawgi, A.K., Bhandarkar, S. and Ojha, G.C. 2017. Agromorphological characterization and morphological based genetic diversity analysis of Rice (Oryza sativa L.) germplasm. Journal of Pharmacognosy and Phytochemistry, 6(6): 75-80.

Parikh, M., Motiramani, N.K., Rastogi, N.K. and Sharma, B. 2012. Agromorphological characterization and assessment of variability in aromatic rice germplasm. Bangladesh J. Agril. Res. 37(1): 1-8.

Pragnya, K., Radha Krishna, K.V., Subba Rao, L.V. and Suneetha, K. 2018. Studies on morphological characterization in Soft Rice (Oryza sativa L.) genotypes. Int.J.Curr.Microbiol.App.Sci. $\quad 7(5)$ : 1348-1374.

Rawte, S. and Saxena, R.R. 2018. Morphological characterization of selected rice (Oryza sativa L.) from Core germplasm group of Chhattisgarh using DUS descriptors. Int.J.Curr.Microbiol.App.Sci. $7(10)$ : 350-357.

Rawte, S. and Saxena, R.R. 2018. Phenotypic Diversity and Correlation analysis for Agro-Morphological Traits in 100 Landraces of Rice (Oryza sativa L.) 
from Chhattisgarh, Int. J. Pure App. Biosci. 6(6): 345-353.

Sajid, M., Khan, S. A., Khurshid, H., Iqbal, J., Muhammad, A., Saleem, N., and Shah, S. M. A. 2015. Characterization of rice (Oryza sativa L.) germplasm through various agro-morphological traits. Scientia, 9(2), 83-88.

Sarawgi, A. K., Subba Rao, L. V., Parikh, M., Sharma, B., and Ojha, G. C. 2013. Assessment of variability of Rice
(Oryza sativa L.) germplasm using agro-morphological

characterization. Journal of Rice Research, 6(1), 14.

Umarani, E., Radhika, K., Padma, V. and Subbarao, L.V. 2017. Agromorphological characterization of Rice( Oryza sativa L.) landraces based on DUS descriptors. Int. J. Pure App. Biosci. 5 (4): 466-475.

\section{How to cite this article:}

Kanushree Nandedkar, A.K. Sarawgi, Mangla Parikh, Ritu R. Saxena and Suman Rawte. 2020. Assessment of Diversity based on Agro-morphological and Quality Characterization of Germplasm Accessions of Rice (Oryza sativa L.). Int.J.Curr.Microbiol.App.Sci. 9(08): 23972408. doi: https://doi.org/10.20546/ijcmas.2020.908.274 